Article

Subscriber access provided by Nottingham Trent University

\title{
Platelet Lysate-Loaded Photocrosslinkable Hyaluronic Acid Hydrogels for Periodontal Endogenous Regenerative Technology
}

\author{
Pedro S. Babo, Ricardo L Pires, Lívia Santos, Albina Franco, Fernando
}

Rodrigues, Isabel B Leonor, Rui L. Reis, and Manuela E. Gomes

ACS Biomater. Sci. Eng., Just Accepted Manuscript • DOI: 10.1021/acsbiomaterials.6b00508 • Publication Date (Web): 20 Dec 2016

Downloaded from http://pubs.acs.org on January 4, 2017

\section{Just Accepted}

"Just Accepted" manuscripts have been peer-reviewed and accepted for publication. They are posted online prior to technical editing, formatting for publication and author proofing. The American Chemical Society provides "Just Accepted" as a free service to the research community to expedite the dissemination of scientific material as soon as possible after acceptance. "Just Accepted" manuscripts appear in full in PDF format accompanied by an HTML abstract. "Just Accepted" manuscripts have been fully peer reviewed, but should not be considered the official version of record. They are accessible to all readers and citable by the Digital Object Identifier (DOI®). "Just Accepted" is an optional service offered to authors. Therefore, the "Just Accepted" Web site may not include all articles that will be published in the journal. After a manuscript is technically edited and formatted, it will be removed from the "Just Accepted" Web site and published as an ASAP article. Note that technical editing may introduce minor changes to the manuscript text and/or graphics which could affect content, and all legal disclaimers and ethical guidelines that apply to the journal pertain. ACS cannot be held responsible for errors or consequences arising from the use of information contained in these "Just Accepted" manuscripts. 


\title{
Platelet Lysate-Loaded Photocrosslinkable Hyaluronic Acid Hydrogels for Periodontal Endogenous Regenerative Technology
}

\author{
Pedro S. Babo ${ }^{1,2}$, Ricardo L. Pires ${ }^{1,2}$, Lívia Santos ${ }^{1,2}$, Albina Franco ${ }^{1,2}$, Fernando Rodrigues ${ }^{2,3}$, \\ Isabel Leonor ${ }^{1,2}$, Rui L. Reis ${ }^{1,2}$ and Manuela E. Gomes ${ }^{1,2 *}$ \\ 13B's Research Group- Biomaterials, Biodegradables and Biomimetics; University of Minho, \\ Avepark- Zona Industrial da Gandra, 4806- 017 Barco GMR, Portugal \\ ${ }^{2}$ ICVS/3B's - PT Government Associate Laboratory, Braga/Guimarães, Portugal \\ ${ }^{3}$ Life and Health Sciences Research Institute (ICVS), School of Health Sciences, University of \\ Minho, Braga, Portugal
}

\begin{abstract}
The integrity and function of the periodontium can be compromised by traumatic injuries or periodontitis. Currently available clinical therapies are able to stop the progression of periodontitis and allow the healing of periodontal tissue. However an optimal strategy capable of restoring the anatomy and functionality of the lost periodontal tissue is still to be achieved.
\end{abstract}


Herein is proposed the development of an injectable hydrogel system able to release a growth factors and cells to the periodontal defect.

This injectable system is based on a photocrosslinkable hydrogel, prepared from methacrylated Hyaluronic Acid (me-HA) and incorporating Platelet Lysate (PL). The delivery of growth factors and cells in situ is expected to enhance regeneration of the periodontium. Various formulations of me-HA containing increasing PL concentrations were studied for achieving the formation of stable photocrosslinkable hydrogels. The produced hydrogels were subsequently characterized to assess mechanical properties, degradation, protein/growth factor release profile, antimicrobial activity and response towards human Periodontal Ligament fibroblasts (hPDLFs). The results demonstrated that it was possible to obtain stable photocrosslinkable hydrogels incorporating different amounts of PL that can be released in a sustained manner. Furthermore, the incorporation of PL improved $(\mathrm{p}<0.02)$ the viscoelastic properties of the hydrogels and enhanced their resilience to the degradation by hyaluronidase (HAase). Additionally, the PL showed to provide antimicrobial properties.

Finally, hPDLFs, either seeded or encapsulated into the developed hydrogels, showed enhanced proliferation over time $(\mathrm{p}<0.05)$, proportionally to the increasing amounts of PL present in the hydrogel formulations.

\begin{abstract}
KEYWORDS
Photocrosslinkable hydrogels, Platelet lysate, Hyaluronic acid, Periodontal ligament, Endogenous regenerative technology
\end{abstract}




\section{INTRODUCTION}

The periodontium is a complex and dynamic oral structure comprising soft and hard tissues, the cementum, a functionally oriented periodontal ligament, alveolar bone and gingiva The main function of this structure is anchoring the teeth to the jaw bones, while withstands the forces originated by the masticatory process ${ }^{1}$. The integrity and function of the periodontium can be compromised by trauma or disease, such as periodontitis, an inflammatory disease predominantly caused by gram-negative bacteria that causes the destruction of these tooth supportive tissues potentially leading to tooth $\operatorname{los} s^{1-2}$.

Current therapeutic options, which include the implantation of autografts, synthetic bone fillers and guided tissue regeneration (GTR), are not able to fully regenerate periodontium morphology and function. In recent years endogenous regenerative technology (ERT) has arisen as a new paradigm in periodontal regeneration. This new concept has its foundations in tissue engineering and aims to induce or encourage periodontal regeneration by superimposing specific chemical (e.g. growth factors) and biophysical cues ${ }^{3}$. These signals are expected to encourage homing of stem and progenitor cells leading to the formation of new periodontal ligament and cementum ${ }^{3}$.

Platelet rich hemoderivatives (PRHds), namely platelet rich plasma and platelet rich fibrin, have been widely investigated for periodontal ERT as important sources of autologous growth factors and provisional fibrin matrices ${ }^{1,3}$. Nevertheless, the traditional PRHds clots retract, impairing the needed stability for periodontal tissue ingrowth ${ }^{4}$. In this research work we propose the development of photocrosslinkable hyaluronic acid hydrogels enriched with platelet lysate as a stable system for the delivery of endogenous GFs, directed for periodontal ERT. 
It is advocated that current ERT scaffolding materials needs sophistication and that should be employed in a patient-tailored fashion using preferably own patients' biological material ${ }^{3}$. In this sense, platelet lysate (PL) offer great potential in regenerative medicine as an alternative source of growth factors $(\mathrm{GFs})^{5-6}$. These PL-origin GFs, include fibroblast growth factor (FGF), vascular endothelial growth factor, platelet-derived growth factor, transforming growth factors$\beta 1$ and $-\beta 2$, insulin-like growth factor, epidermal growth factor, epithelial cell growth factor, hepatocyte growth factor and bone morphogenetic proteins ${ }^{7-9}$ are known to be involved in essential stages of wound healing and regenerative processes such as chemotaxis, cell proliferation and differentiation ${ }^{10-11}$. Moreover, platelets release numerous cell adhesion molecules (fibrin, fibronectin and vitronectin) which can provide a provisional matrix for the adhesion and migration of cells ${ }^{10}$. In addition, platelet concentrates (PCs) have also been reported to exhibit antimicrobial properties ${ }^{12}$ and the PL, as a product of PCs activation, is expected to have the same antimicrobial properties, contributing for the prophylaxis of the wound site. In fact, the use of PL holds several advantages over other (PRHds) which include the ease to standardize of the production process and the higher consistency in GF content between batches $^{5}$, that is expected to yield more predictable clinical outcomes.

Since PL is obtained as a liquid solution, it was incorporated in a photocrosslinkable HA matrix. HA is a glycosaminoglycan copolymer of D-glucuronic acid and N-acetyl-d-glucosamine that is present in connective tissues and plays an important role in several cellular processes including, cell proliferation, morphogenesis, inflammation, and wound repair ${ }^{13}$. HA-based biomaterials have demonstrated positive results for several potential applications in the regeneration of hard or soft tissues ${ }^{14}$. Moreover, given HA anti-inflammatory, anti-edematous, 
and anti-bacterial effects, it has been also proposed for the treatment of lesions caused by periodontal diseases ${ }^{15-17}$.

The aim is to characterise these PL-rich scaffolds with regard to mechanical properties, release of proteins, periodontal cell response and antimicrobial action against dental plaque bacteria. This new ERT scaffold offers a new and promising periodontal treatment modality that should encourage tissue regeneration through the release of PL-derived GFs while providing concomitant anti-microbial action. Furthermore, functionalization of HA with methacrylic groups allows the production in situ of stable photopolymerizable hydrogels, enabling the application in periodontal defects in a clinical scenario.

\section{MATERIALS AND METHODS \\ Materials}

HA obtained from Streptococcus equi $(\mathrm{Mw}=1.5$ to $1.8 \mathrm{MDa})$, methacrylic anhydride Irgacure 2959 (2-hydroxy-4-(2-hydroxyethoxy)-2-methylpropiophenone), hyaluronidase type IV from bovine origin (HAase), Phosphate Buffered Saline (PBS), phalloidin-tetramethylrhodamine B isothiocyanate 4,6-diamidino-2-phenylindole, dilactate (DAPI) and the dialysis tubing cellulose membrane were all purchased from Sigma (Sigma-Aldrich, USA). Sodium hydroxide (NaOH) and hydrochloride acid $(\mathrm{HCl})$ were purchased from VWR Chemicals (BDH, Prolabo international, USA). Alpha MEM ( $\alpha$-MEM) culture medium and fetal bovine serum (FBS) were purchased from Gibco (Life Technologies, UK). Deuterium oxide $\left({ }^{2} \mathrm{H}_{2} \mathrm{O}\right)$ was purchased from LaborSpirit lda (PT) and the polydimethylsiloxane (PDMS) from Down Corning (USA). The Muller-Hinton agar plate was obtained from Oxoid (UK). 


\section{Preparation of Platelet Lysate (PL)}

PL was obtained from different lots of platelet concentrates provided by Serviço de Imunohematologia do Centro Hospitalar de São João (CHSJ, Porto, Portugal), based on a previously established protocol. To produce PL, batches of platelet concentrates obtained by plasma apheresis with a density of $10^{6}$ cells/ $\mu \mathrm{L}$ and biologically qualified according to Portuguese legislation (Decreto-Lei No. 100/2011) were processed as previously described ${ }^{18-19}$. Very briefly, platelet concentrates from three different donors were pooled and exposed to three repeated freezing and thaw cycles (frozen with liquid nitrogen and thawed in a $37^{\circ} \mathrm{C}$ water bath) to promote the lysis of the platelets and release of GFs. Afterwards, the lysis product was centrifuged at $1400 \mathrm{rcf}$ for $10 \mathrm{~min}$ and the supernatant stored at $-20^{\circ} \mathrm{C}$ until further use ${ }^{18-19}$.

\section{Methacrylation of Hyaluronic Acid (HA)}

The method followed for the methacrylation of HA was based on a previously described protocol $^{20}$, (depicted in Figure 1A), consisting in the addition between 5- to 10-fold molar excess (5x and 10x) of methacrylic anhydride (MA) to a solution of 1 wt $\%$ HA in distilled water $\left(\mathrm{dH}_{2} \mathrm{O}\right)$. The $\mathrm{pH}$ was adjusted between 8 and 8.5 with $5 \mathrm{~N} \mathrm{NaOH}$ added dropwise. The reaction occurred during 24 hours at $4^{\circ} \mathrm{C}$ provided by an ice bath. Subsequently, the reaction products were precipitated using cold ethanol $\left(\right.$ at $\left.-20^{\circ} \mathrm{C}\right)$. Then the precipitate was dissolved in $\mathrm{dH}_{2} \mathrm{O}$ and dialysed using a membrane with a cut-off of $14,000 \mathrm{kDa}$ for a week against mili-Q water, replaced 3 times a day, to remove the unreacted reagents and by-products. Finally, the solution was filtered, frozen at $-80^{\circ} \mathrm{C}$ and the methacrylated HA (me-HA) recovered upon lyophilisation.

\section{Characterization of the me-HA}


Fourier transform infrared spectroscopy (IR-Prestige-21, FTIR Shimadzu) was used to record the infrared spectra of HA and me-HA. Briefly, a small portion of each batch was mixed with potassium bromide, and processed into pellets. The spectra were obtained in the range of 400 to $4000 \mathrm{~cm}^{-1}$ at a $4 \mathrm{~cm}^{-1}$ resolution with 32 scans. ${ }^{1} \mathrm{HNMR}$ spectra were recorded with a Varian Inova 500 at $70^{\circ} \mathrm{C}$. me-HA solutions were prepared for analysis by dissolving $5 \mathrm{mg}$ of me-HA in $1 \mathrm{~mL}$ of ${ }^{2} \mathrm{H}_{2} \mathrm{O}$. The degree of methacrylation (Dmet) was defined as the percentage of methacryloyl groups per HA disaccharide repeat unit and was calculated from the ratio of the relative peak integration of the methacrylate protons (peaks at $\sim 6.20, \sim 5.77$, and $\sim 2.05 \mathrm{ppm}$ ) and HA’s methyl protons $(\sim 1.98 \mathrm{ppm})$.

\section{Development of the photocrosslinkable me-HA hydrogels incorporating PL}

The development of the photocrosslinkable me-HA hydrogels incorporating PL was optimized by changing the HA (5x and 10x MA molar excess) solution concentration ( 1 and $2 \mathrm{wt} \%$ ), the concentration of photoinitiator Irgacure $2959(0.1$ and $0.2 \mathrm{wt} / \mathrm{v} \%)$, the power of the UV light, the distance to the UV light source, and the concentration of PL incorporated in the solvent solution (Table 1). PL was incorporated in the solvent solution in increasing volumetric concentrations ranging from pure water $(0 \% \mathrm{PL})$ to pure PL $(100 \% \mathrm{PL})$. To obtain hydrogels, dry me-HA was dissolved in the solvent solution containing the photoinitiator. Then, $25 \mu \mathrm{L}$ of me-HA solution were injected into a circular (5mm diameter) PDMS mold and exposed to a UV light (Omnicure series 2000 EXFO S2000-XLA, Omnicure, Canada) to trigger the photocrosslinking, producing disk-shaped hydrogels. The produced formulations, incorporating 0, 50 and 100\% PL, were designated $\mathrm{PL}_{0}, \mathrm{PL}_{50}$, and $\mathrm{PL}_{100}$, respectively. 
Table 1. Summary of the formulations studied for the optimization of the hyaluronic acid hydrogels incorporating PL (HAPL). The concentrations of me-HA and Irgacure 2959 are presented as weight/volume percentage. The PL concentrations are volumetric concentrations of pure PL $(100 \% \mathrm{PL})$ in water $(0 \% \mathrm{PL})$. All the formulations described below were prepared using both the batches of me-HA (5x and 10x molar excess).

\begin{tabular}{|c|c|c|}
\hline $\begin{array}{l}\text { me-HA } \\
(\mathrm{wt} / \mathrm{v} \%)\end{array}$ & $\begin{array}{l}\text { Irgacure } \\
(w t / v \%)\end{array}$ & $\begin{array}{l}\text { PL } \\
(\mathbf{v} / \mathbf{v} \%)\end{array}$ \\
\hline \multirow{6}{*}{$1 \%$} & \multirow{3}{*}{$0,10 \%$} & $0 \%$ \\
\hline & & $50 \%$ \\
\hline & & $100 \%$ \\
\hline & \multirow{3}{*}{$0,20 \%$} & $0 \%$ \\
\hline & & $50 \%$ \\
\hline & & $100 \%$ \\
\hline \multirow{6}{*}{$2 \%$} & \multirow{3}{*}{$0,10 \%$} & $0 \%$ \\
\hline & & $50 \%$ \\
\hline & & $100 \%$ \\
\hline & \multirow{3}{*}{$0,20 \%$} & $0 \%$ \\
\hline & & $50 \%$ \\
\hline & & $100 \%$ \\
\hline
\end{tabular}

\section{Characterization of the HAPL hydrogels}

Only the 10x me-HA batch allowed obtaining the hydrogels by photopolymerization, using either 0.1 or $0.2 \%$ of photoinitiator, so this batch was selected for all further studies. Considering that Igacure 2959 presents some cytotoxicity ${ }^{21}$, it was also decided to use the lower photoinitiator concentration for the following characterization steps.

\section{Evaluation of the mechanical properties by DMA}

The viscoelastic properties of the developed hydrogels $\left(\mathrm{PL}_{0}, \mathrm{PL}_{50}\right.$ and $\mathrm{PL}_{100}$ with $1 \%$ or $2 \%$ of me-HA and with $0.1 \%$ of Irgacure) were evaluated by dynamic mechanical analysis (DMA) 
(TRITEC8000B, Triton Technology, UK), equipped with the compressive mode. DMA spectra were obtained during a frequency scan ranging between 0.1 and $15 \mathrm{~Hz}$ for all time points. The experiments were performed under constant strain amplitude, corresponding to approximately $1 \%$ of the original height of the sample. Samples were tested while immersed in PBS and at $37^{\circ} \mathrm{C}$, to simulate the physiological conditions.

\section{Swelling and weight loss}

The results obtained from the DMA analysis revealed better mechanical properties for the $2 \%$ me-HA formulation and thus this was selected for the subsequent studies, namely degradation, protein release and cell response. Thus, formulations of hydrogels with increasing concentrations of PL ( $\mathrm{PL}_{0}, \mathrm{PL}_{50}$ and $\left.\mathrm{PL}_{100}\right)$, were prepared into disc-shaped samples of $5 \mathrm{~mm}$ in diameter and 1 mm thickness, as above described, and placed in 24 wells plate.

Periodontal ligament fibroblasts express hyaluronidase (HAase) and generate HAase activity that regulates extracellular hyaluronan metabolism ${ }^{22}$. Given the presence of this enzyme in the periodontium, the degradation promoted by a HAase was investigated. Similar assay was conducted in PBS. Each sample was incubated in $1.6 \mathrm{~mL}$ of $\mathrm{PBS}$ at $37^{\circ} \mathrm{C}, \mathrm{pH} 7.4$. For the enzymatic degradation assays, the same formulations were incubated at $37^{\circ} \mathrm{C}$ in $1.6 \mathrm{~mL}$ of a HAase solution of $100 \mathrm{U} / \mathrm{mL}$ in PBS.

The assays were carried out using 4 samples of each formulation immersed in each of the solutions. The samples were retrieved after 1, 3, 7, 14 and 21 days of incubation.

The wet weight of the samples was registered (PI-214 analytical balance, Denver Instrument Company, USA) at each pre-determined time point. The dry weight of the samples was also 
registered after allowing samples to dry overnight at $37^{\circ} \mathrm{C}$. The percentage of weight loss was calculated according to equation (1):

$$
\text { Weight loss }=\frac{(m i-m f)}{m i} \times 100
$$

where $m_{i}$ is the initial weight and $m_{f}$ the final weight.

The water uptake ratio was also calculated following equation (2) by dividing each sample wet mass ( $m w e t)$ by the final dry hydrogel mass $(m d r y)$.

$$
\text { Water uptake ratio }=\frac{m w e t}{m d r y} \times 100
$$

\section{Quantification of protein release}

Protein release from $\mathrm{PL}_{0}, \mathrm{PL}_{50}$ and $\mathrm{PL}_{100}$ was quantified after $30 \mathrm{~min}, 1 \mathrm{~h}, 4 \mathrm{~h}, 8 \mathrm{~h}, 1,7,14$ and 21 days of incubation in $\mathrm{PBS}$ at $37^{\circ} \mathrm{C}$. For this purpose, at each time point, a volume of supernatant was collected and stored at $-20^{\circ} \mathrm{C}$. The total protein content was quantified using a micro BCA protein assay (Thermo Fischer Scientific, USA), following the manufacturer's instructions. Additionally, the release of fibroblast growth factor-2 (FGF-2), present in the PL, was also quantified using an enzyme-linked immunosorbent assay kit (Human FGF-basic, ELISA Development Kit, by PeproTech, USA), according to manufacturer's instructions.

\section{Evaluation of the response of human periodontal ligament fibroblasts (hPDLFs)}


The response of hPDLFs to the photocrosslinked me-HA/PL hydrogels was assessed upon either encapsulation or seeding of the cells onto the hydrogels surface and further cultured for up to 14days.

The hPDLFs (ScienCell Research Laboratories) at passage 3 were seeded on disc-shaped (5 mm diameter) samples of the formulations $\mathrm{PL}_{0}, \mathrm{PL}_{50}$ and $\mathrm{PL}_{100}$ produced as previously described, at a cell density of $5 \times 10^{4} \mathrm{~cm}^{-2}$. A $50 \mu \mathrm{L}$ drop of a cellular suspension containing $1 \times 10^{4}$ cells was seeded on the surface of each sample, previously placed in a 24 wells plate, and allowed to adhere for $1 \mathrm{~h}$. After this period, $450 \mu \mathrm{L}$ of $\alpha$-MEM basal medium (supplemented with $10 \%$ of FBS and $1 \%$ antibiotic-antimycotic) were added to each well. The 24 wells plates containing the cell-seeded hydrogels were further incubated at $37^{\circ} \mathrm{C}, 5 \% \mathrm{CO}_{2}$ for $1,4,7$ and 14 days, renewing the culture medium every 3 days. Cells cultured on polystyrene cover-slips (Sarstedt) were employed as positive control.

For the encapsulation, hPDLFs cells were resuspended in $2 \%$ me-HA solutions containing 0 , 50 and $100 \%$ PL to obtain a final cell density of $4 \times 10^{6}$ cells.ml $l^{-1}$. Then, $25 \mu \mathrm{L}\left(1 \times 10^{5}\right.$ cells $)$ of the cellular suspension in each hydrogel solution formulation was injected into circular moulds (5mm diameter) and exposed to UV light, as previously described to obtain the hydrogel samples. The cell-laden hydrogels were subsequently transferred to individual wells of 24-well plates, each one containing $500 \mu \mathrm{L}$ of basal medium. The 24 -wells plates were incubated at $37^{\circ} \mathrm{C}, 5 \% \mathrm{CO}_{2}$ for $1,4,7$ and 14 days renewing the culture medium every 3 days.

The metabolic activity of the cells seeded/encapsulated in the hydrogels and further cultured was evaluated using the Alamar blue assay (AbDseroTec, USA), following the manufacturer's instructions. Briefly, at each time point, the culture medium was discarded, the samples were washed twice with PBS and then incubated in a 10\% Alamar blue solution in basal medium (450 
$\mu \mathrm{L}$ of basal medium, and $50 \mu \mathrm{L}$ of Alamar blue) at $37^{\circ} \mathrm{C}, 5 \% \mathrm{CO}_{2}$ for $150 \mathrm{~min}$. The fluorescence

of the supernatant solution was read in triplicates in a microplate reader (Synergy HT, Biotek, USA-) at $560 \mathrm{~nm}$ of excitation and $590 \mathrm{~nm}$ of emission.

The cellular proliferation was also evaluated as a function of the dsDNA quantification using the PicoGreen dsDNA quantification kit, according to manufacturer's specifications (Life Technologies, USA).

Finally, the morphology and the migration of the cells either encapsulated or seeded on the surface of the hydrogels were investigated by confocal microscopy, upon staining with DAPI and phalloidin. For this purpose, samples retrieved after each of the pre-set culturing times were fixed with $10 \%$ formalin (in PBS) for $30 \mathrm{~min}$ at room temperature. Afterwards, the samples were washed 2 times with PBS to remove the formalin and $300 \mu \mathrm{L}$ of phalloidin solution $(1: 100$ in PBS) were added per well and incubated 1 hour at room temperature. Then phalloidin solution was discarded and the samples were washed 3 times with PBS. A DAPI solution (1:1000 in PBS) was prepared and $300 \mu \mathrm{L}$ were added per well and incubated 5 min. The samples were washed 3 times and the prepared for visualization under a confocal microscopy (TCS SP8 from Leica Mycrosystems CMS GmbH) with vectashield mounting medium.

\section{Antimicrobial Assay}

The antimicrobial activity of PL soluble factors released form from the HA hydrogels was evaluated using the radial diffusion assay, according to Kirby-Bauer method ${ }^{23}$. Five different bacteria species were used: the gram-positive bacteria Bacillus megaterium (Internal collection), Methicillin Resistant Staphylococcus aureus (MRSA) (Internal collection), and Vancomycin Resistant Staphylococcus aureus (VRSA) (internal collection) and the gram-negative species 
Pseudomonas aeruginosa T6BT12, Escherichia coli DH5 $\alpha$ ) and the fungus Candida albicans (Internal collection). With the exception of $P$. aeruginosa, which was isolated from environmental samples, all the other microorganisms were isolated from clinical samples. Prior to the antimicrobial activity testing, these microorganisms were cultured aerobically in LuriaBertani broth at $37^{\circ} \mathrm{C}$ overnight with agitation $(150 \mathrm{rpm})$. Afterwards, they were centrifuged at $8000 \mathrm{rpm}$ for $5 \mathrm{~min}$, and washed three times with PBS. Microbial cultures were adjusted to a concentration corresponding to ca. $10^{7} \mathrm{CFU} \cdot \mathrm{mL}^{-1}$, and pipetted with $0.4 \%$ agar into a petri dish containing $5 \mathrm{~mL}$ of Muller-Hinton (MH) Agar plate.

The $\mathrm{PL}_{0}, \mathrm{PL}_{50}$ and $\mathrm{PL}_{100}$ hydrogels and the negative control (PBS) were placed on $\mathrm{MH}-$ agar plates and cultured with each of microbial strain at $37^{\circ} \mathrm{C}$ for $16 \mathrm{~h}$, upon which the inhibition halo measure and the general macroscopic response was recorded. Experiments were performed in triplicate.

\section{Statistical analysis}

All the experiments were performed with at least three replicates. All the cell culture experiments were performed simultaneously in order to reduce the variability intra-assay and 3 independent studies were performed, exactly as described. Results are expressed as mean \pm standard error of the mean (SEM). Statistical analysis was performed by repeated measures Twoway ANOVA comparison test $(* \mathrm{p}<0.05$, ** $\mathrm{p}<0.01$ and $* * * \mathrm{p}<0.001$ for statistically significant differences) using the software Graph Pad Prism 6.

\section{RESULTS}

\section{Development of the photocrosslinkable me-HA hydrogels}




\section{HA methacrylation}

In this study, unmodified hyaluronan was methacrylated reacting a $1 \% \mathrm{HA}$ aqueous solution at $\mathrm{pH} 8$, with $5 \mathrm{x}$ and $10 \mathrm{x}$ of molar excess of MA for $24 \mathrm{~h}$ at $4^{\circ} \mathrm{C}$.

The methacrylation of HA was confirmed by the FTIR spectra, where the deep peak at 1715 $\mathrm{cm}^{-1}$ represents the carbonyl ester group resultant from the methacrylation (Figure 1C). Moreover, the ${ }^{1} \mathrm{HNMR}$ spectra of the me-HA batches (Figure 1D) exhibited the presence the characteristic peaks corresponding to the two protons of the double bond region $(\delta 5.77$ and 6.20 ppm) of the MA group absent in the non-modified HA spectrum. 
A)

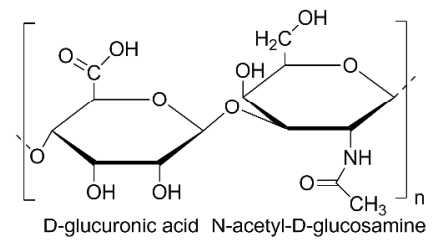

Hyaluronic acid
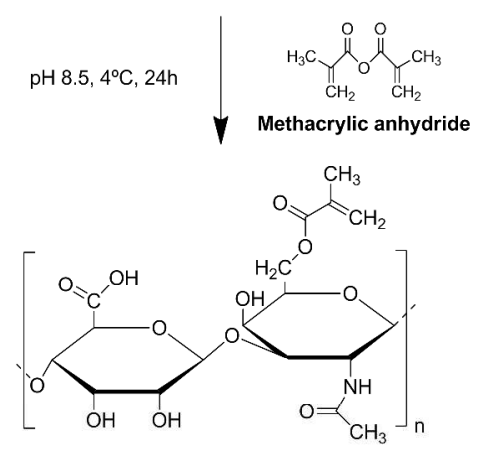

Methacrylated Hyaluronic acid

B)

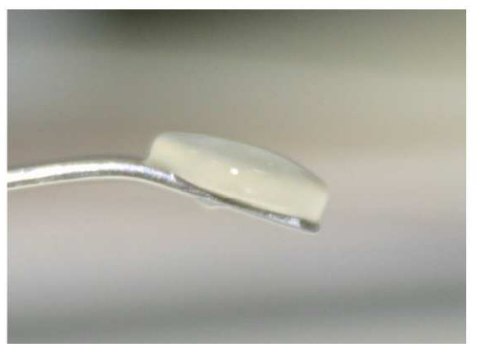

C)

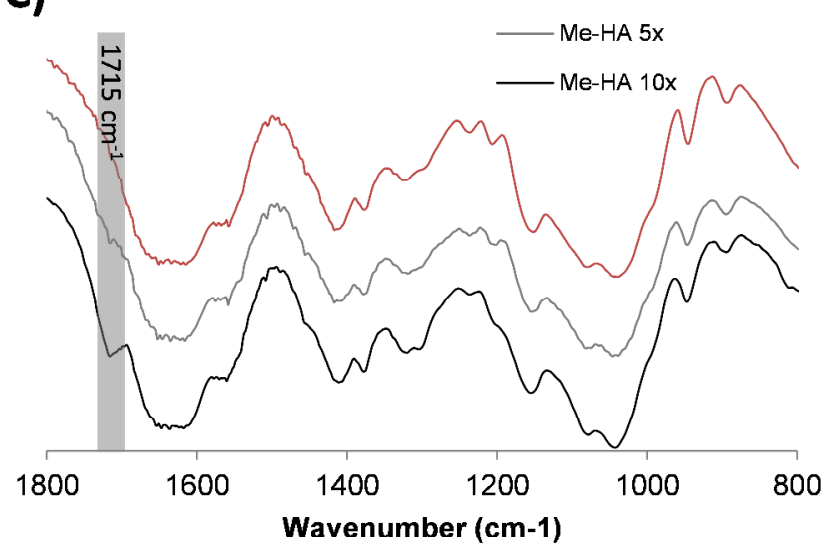

D)
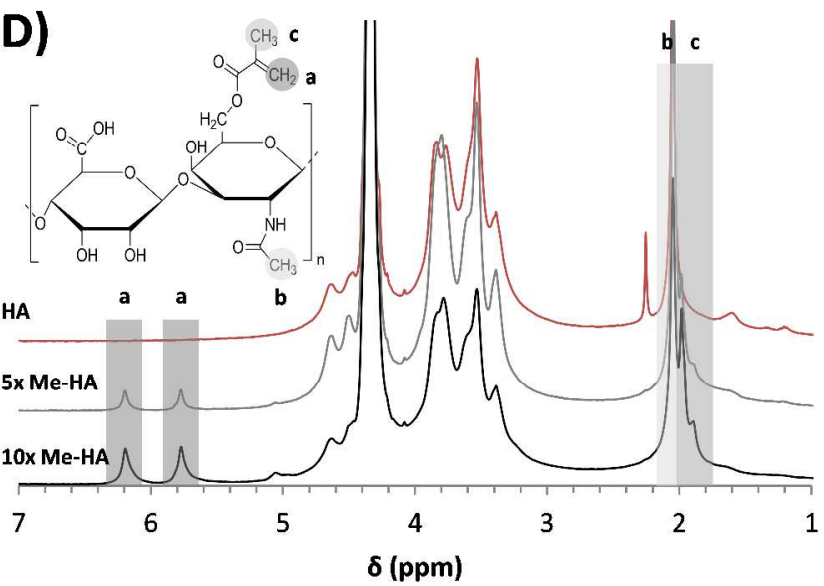

Figure 1. A) Scheme of the methacrylation process of Hyaluronic acid using methacrylic anhydride. B) Representative image depicting a typical me-HA/PL hydrogel obtained by photopolimerization. C) FTIR Spectra of HA and me-HA produced with 5 and 10x molar excess of (5X and 10X me-HA). D) ${ }^{1}$ HNMR spectra of HA, 5x me-HA and 10x me-HA: a) Vynil groups of MA ( $\delta 5.77-6.20 \mathrm{ppm})$; b) Methyl group of the N-AcetyL-d-Glucosamine $(\delta 2.05$ ppm); and c) methyl group of MA ( $\delta 1.94 \mathrm{ppm})$.

The degree of methacrylation was calculated from the ratio of the relative peak integration of the methacrylate protons (peaks at $\sim 6.20, \sim 5.77$, and $\sim 2.05 \mathrm{ppm}$ ) and the methyl protons of $\mathrm{N}$ - 
Acetyl-D-glucosamine ( 1.98 ppm). A Dmet of 14\% was obtained for the me-HA batch produced with $5 \mathrm{x}$ excess of MA (5x me-HA), while the batch produced with 10x excess MA (10x me-HA) presented a Dmet of $24 \%$.

\section{Mechanical properties of the developed hydrogels}

Dynamic mechanical analysis (DMA) experiments were performed in a hydrated environment at $37^{\circ} \mathrm{C}$, in an array of biologically relevant frequencies, in order to assess the viscoelastic properties of the samples in a physiological-like environment. Both storage (elastic) modulus, $E^{\prime}$, and the loss factor, $\tan \delta$, were obtained at different frequencies. E' is a measure of the materials stiffness. The loss factor is the ratio of the amount of energy dissipated (viscous component) relative to energy stored (elastic component); $\tan \delta=E^{\prime} / E^{\prime \prime}$.

The obtained results (Figure 2) showed the effect of different concentrations of me-HA and/or PL on the stiffness of the developed hydrogels. When the concentration of me-HA was increased from $1 \%$ to $2 \%$ the elastic storage modulus of the hydrogels also increased above three to four times, from approximately $100 \mathrm{kPa}$ to $428-600 \mathrm{kPa}$, in formulations incorporating PL (PL 50 and $\mathrm{PL}_{100}$ ). The concentration of PL in the hydrogels also showed to influence the elastic modulus that was found to increase proportionally with the amount of PL. The formulation that exhibited the highest elastic modulus corresponds to the formulation containing $2 \%$ of me-HA dissolved in $100 \%$ PL. 
A)

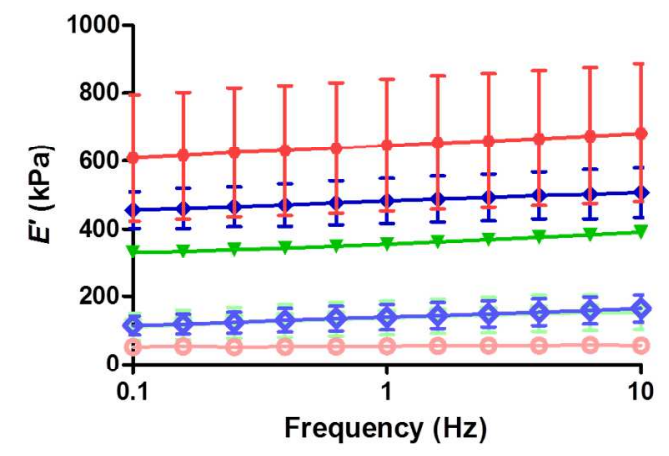

C)

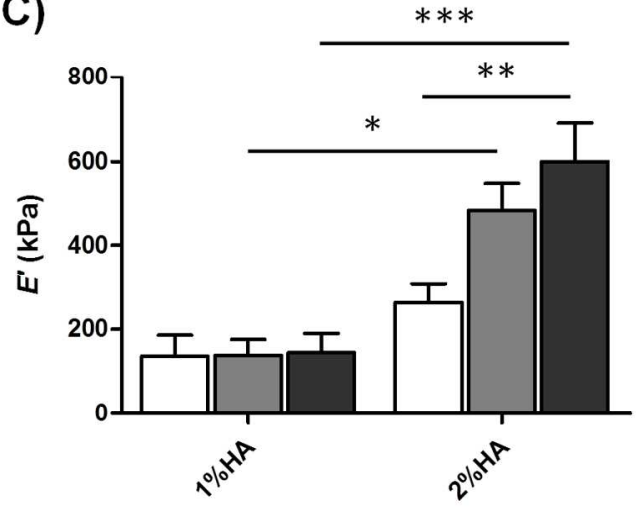

B)

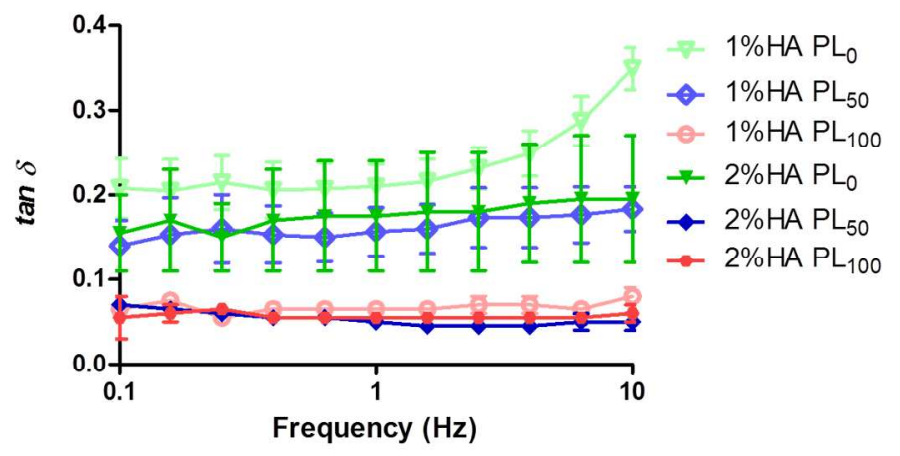

D)

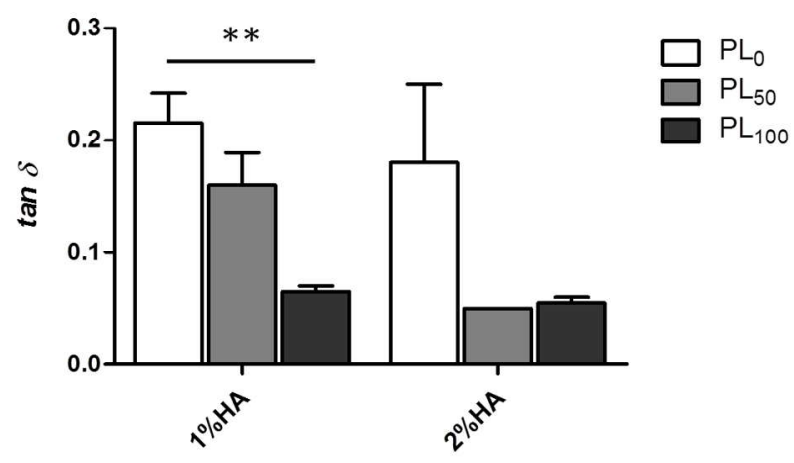

Figure 2. Variation of elastic (E') modulus A) and loss factor $(\tan \delta$ ) B) with frequency of $1 \%$ and $2 \% \mathrm{HA}$ hydrogels incorporating $0 \%, 50 \%$ and $100 \% \mathrm{v} / \mathrm{v} \mathrm{PL}\left(\mathrm{PL}_{0}, \mathrm{PL}_{50}\right.$ and $\left.\mathrm{PL}_{100}\right)$ measured by dynamic mechanical analysis. Differences observed on elastic (E') modulus C) and loss factor $(\tan \delta) \mathrm{D})$ at $1 \mathrm{~Hz} .{ }^{*} \mathrm{p}<0.05, * * \mathrm{p}<0.02 ; * * * \mathrm{p}<0.001$

\section{Degradation behavior}

The weight loss and swelling ratio profiles of the $\mathrm{PL}_{0}, \mathrm{PL}_{50}$ and $\mathrm{PL}_{100}$ hydrogels after incubation in PBS or HAase $(100 \mathrm{U} / \mathrm{mL})$ solution at $37^{\circ} \mathrm{C}$ for $1,3,7$ and 14 days are presented in Figure 3. 


\section{Weight loss}

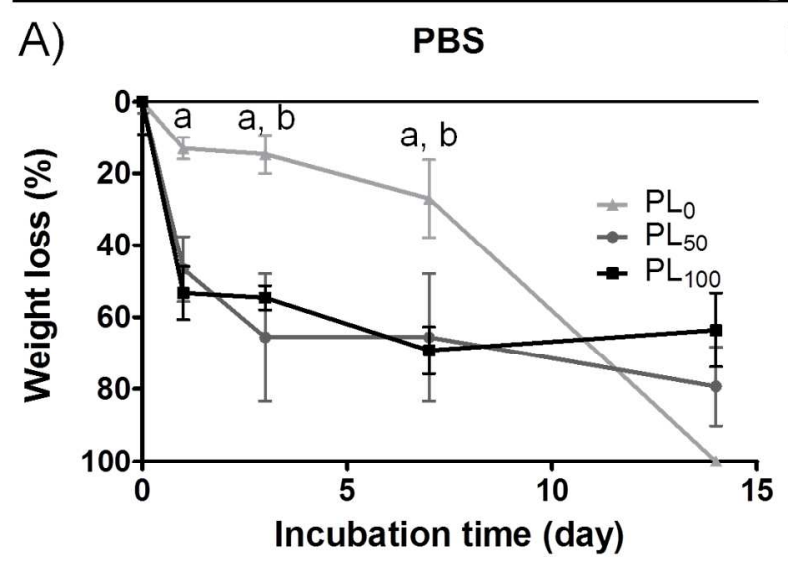

B)

HAase

\section{Swelling}

C)

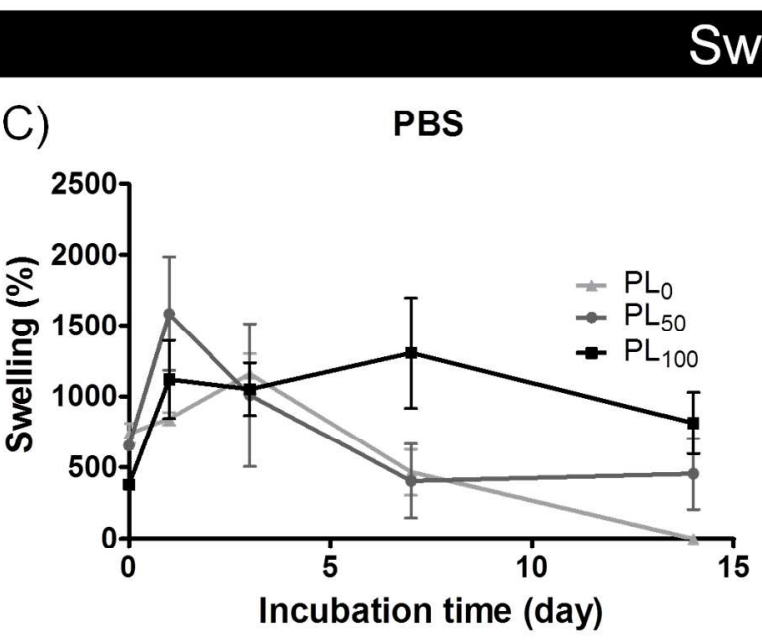

D)

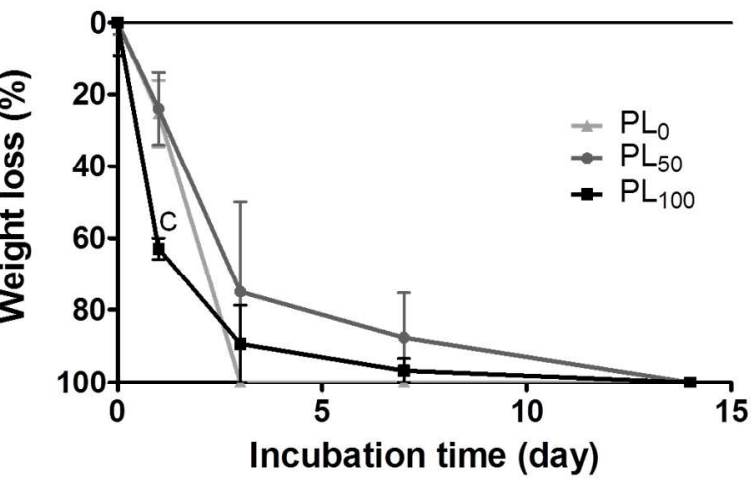

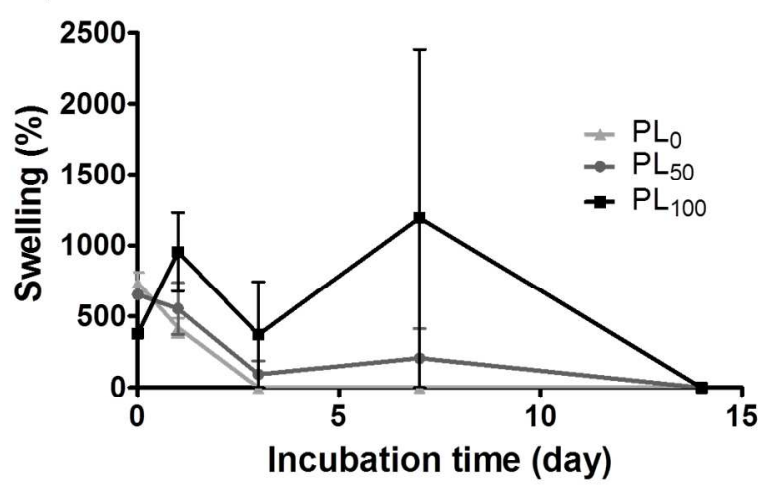

Figure 3. Weight loss $(\mathrm{A}$ and $\mathrm{B})$ and Swelling ratio $(\mathrm{C}$ and $\mathrm{D})$ profile of $\mathrm{PL}_{0}, \mathrm{PL}_{50}$ and $\mathrm{PL}_{100}$ hydrogels in: PBS (A and C) and in HAase solution (100U/ ml) (B and D). a) statistically different $(\mathrm{p}<0.05)$ from $\left.\mathrm{PL}_{100} ; \mathrm{b}\right)$ statistically different $(\mathrm{p}<0.05)$ from $\left.\mathrm{PL}_{50} ; \mathrm{c}\right)$ statistically different $(\mathrm{p}<0.05)$ from $\mathrm{PL}_{0}$ and $\mathrm{PL}_{50}$

\section{Weight loss}

Overall, the results obtained showed that the incorporation of PL in me-HA hydrogels influences its stability. Although the $\mathrm{PL}_{0}$ hydrogels showed lower weight loss until the $7^{\text {th }}$ day of immersion in PBS, they were completely degraded after 14 days (Figure 3A). On the other hand, 
despite the weight loss profile of the formulations incorporating PL is characterized by an initial loss of around $70 \%$ of the dry weight in the first 3 days, the $\mathrm{PL}_{50}$ and $\mathrm{PL}_{100}$ hydrogels tend to be more stable along immersion time in PBS.

The weight loss results obtained upon immersion in HAase, revealed that $\mathrm{PL}_{100}$ formulation displays higher degradability, upon the first day. Nevertheless, it was found that samples containing PL were only completely degraded after 14 days, while all the hydrogels of the $\mathrm{PL}_{0}$ formulation were completely degraded after only 3 day of immersion in the enzymatic solution.

\section{Swelling ratio}

In the beginning of the assay, the swelling of freshly produced $\mathrm{PL}_{100}$ hydrogels was significantly lower than the formulations with lower PL concentration. When immersed in the PBS solution the $\mathrm{PL}_{0}$ and $\mathrm{PL}_{50}$ hydrogels, didn't show significant statistical differences among them for all the time points studied. Accordingly, both hydrogels formulations presented a similar profile characterized by a peak around day $1\left(1500 \%\right.$ for $\left.\mathrm{PL}_{50}\right)$ and day $3(1000 \%$ for $\mathrm{PL}_{0}$ ), followed by a decrease of swelling until the end of the assay, due to the total degradation of the material. On the other hand, $\mathrm{PL}_{100}$ hydrogels had a later peak at day 7 , reaching near $1400 \%$ of swelling.

Regarding the swelling in HAase solution, the values were statistically similar for $\mathrm{PL}_{0}, \mathrm{PL}_{50}$ and $\mathrm{PL}_{100}$ hydrogels. Nevertheless, while the formulations $\mathrm{PL}_{0}$ and $\mathrm{PL}_{50}$ depicted a similar behavior, presenting a constant decrease in the swelling values from the beginning of the assay, the $\mathrm{PL}_{100}$ formulation reached an average swelling of $1400 \%$ at day 7 , before starting to decrease. 


\section{Protein release}

The total amount of protein released from me-HA/PL hydrogels over time is represented in Figure 4.

\section{Total Protein release}

A)
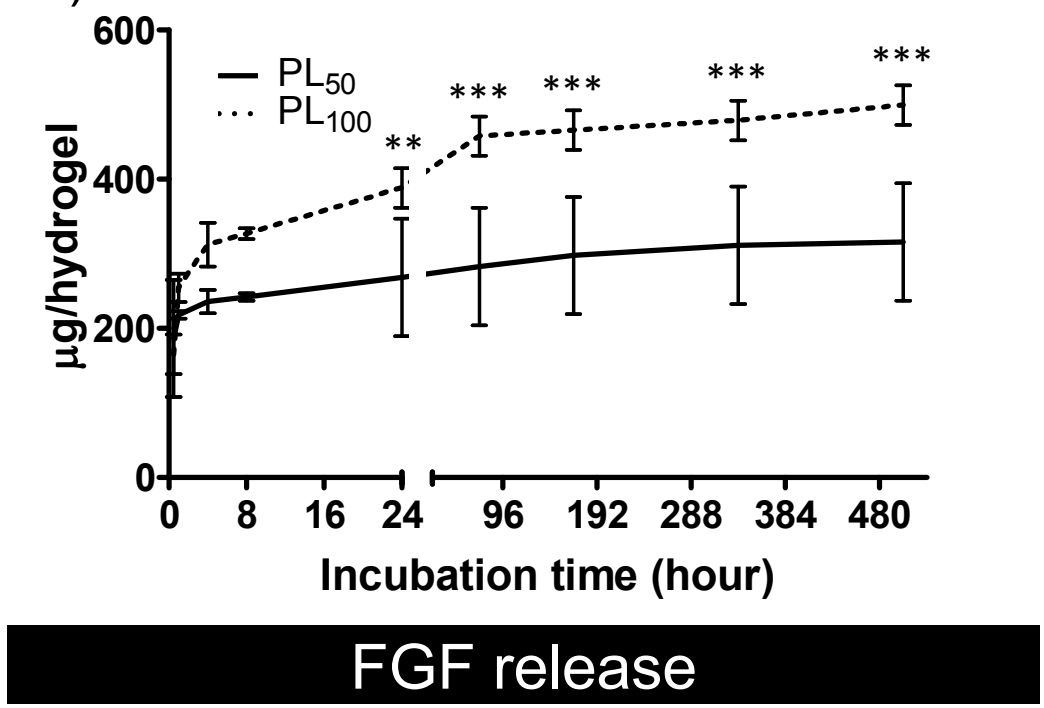

B)

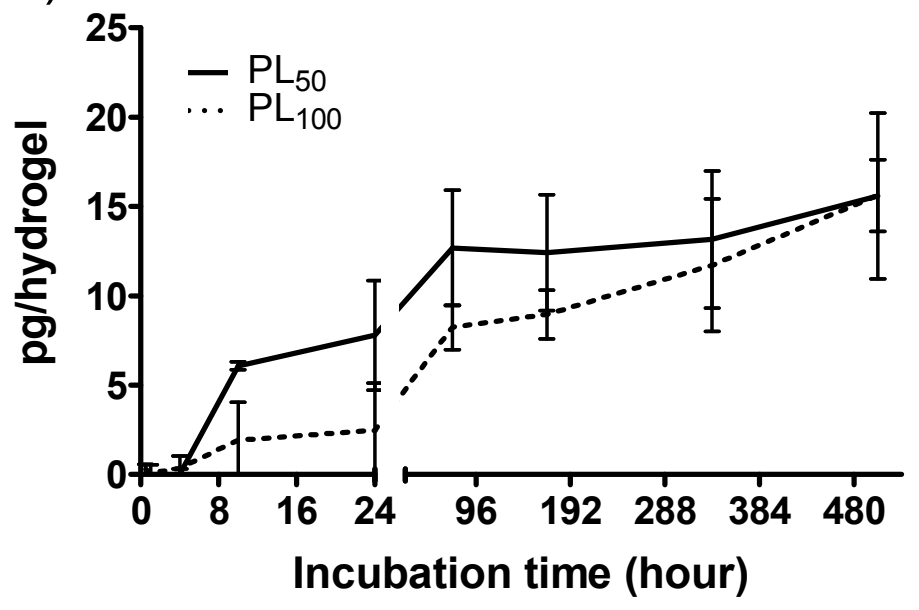

Figure 4. Total protein released from the hydrogels containing PL, assessed using the Pierce ${ }^{\circledR}$ BCA protein assay kit (A) incubated in PBS. Fibroblasts Growth Factor (FGF) release, assessed 
using the PeproTech ELISA Development kit (B) incubated in HAase solution (100U/ml). ** $\mathrm{p}<0.02 ; * * * \mathrm{p}<0.001$

Both $\mathrm{PL}_{50}$ and $\mathrm{PL}_{100}$ hydrogels displayed a similar release profile that is characterized by an initial "burst" of protein released during the first hour, that represents around $15 \%$ for $\mathrm{PL}_{100}$ hydrogels and $25 \%$ for $\mathrm{PL}_{50}$ hydrogels of the total protein contained, followed by a sustained release up to 14 days. While no statistically significant differences were observed between the formulations during the first day of release, there was a substantial difference in the amount of protein released by the $\mathrm{PL}_{100}$ formulation, which is proportional with the amount of protein incorporated in the formulations.

In order to evaluate the release of PL-specific GFs from the developed HA hydrogels, and the interaction of the GFs with the HA mesh, hydrogels were incubated either in PBS or in 100 $\mathrm{U} / \mathrm{mL}$ HAase solution and the release products were quantified by ELISA.

The results for the release of FGF-2, depicted in Figure 4B, showed that the $\mathrm{PL}_{50}$ and $\mathrm{PL}_{100}$ had a different profile for FGF-2 release. The FGF-2 released by $\mathrm{PL}_{50}$ was characterized by an initial burst of release up to day 3, as observed. After day 3, the release kinetics reached an apparent plateau, and a slow sustained delivery remained up to day 21 . On the other hand, $\mathrm{PL}_{100}$ hydrogels showed a sustained release, progressing in a linear way, during all the duration of the assay, without signs of deceleration. Nevertheless, despite the $\mathrm{PL}_{100}$ hydrogels have higher amount of total protein incorporated, they depicted a FGF-2 release similar to the PL ${ }_{50}$ hydrogel.

\section{Cell response to the developed hydrogels}


The response of hPDLFs, either surface seeded or encapsulated onto the $\mathrm{PL}_{0}, \mathrm{PL}_{50}$ and $\mathrm{PL}_{100}$ hydrogels was assessed. In both the cases, the increasing amounts of PL in the hydrogels had a positive effect in the cells metabolic activity and proliferation rate as shown in Figure 5.
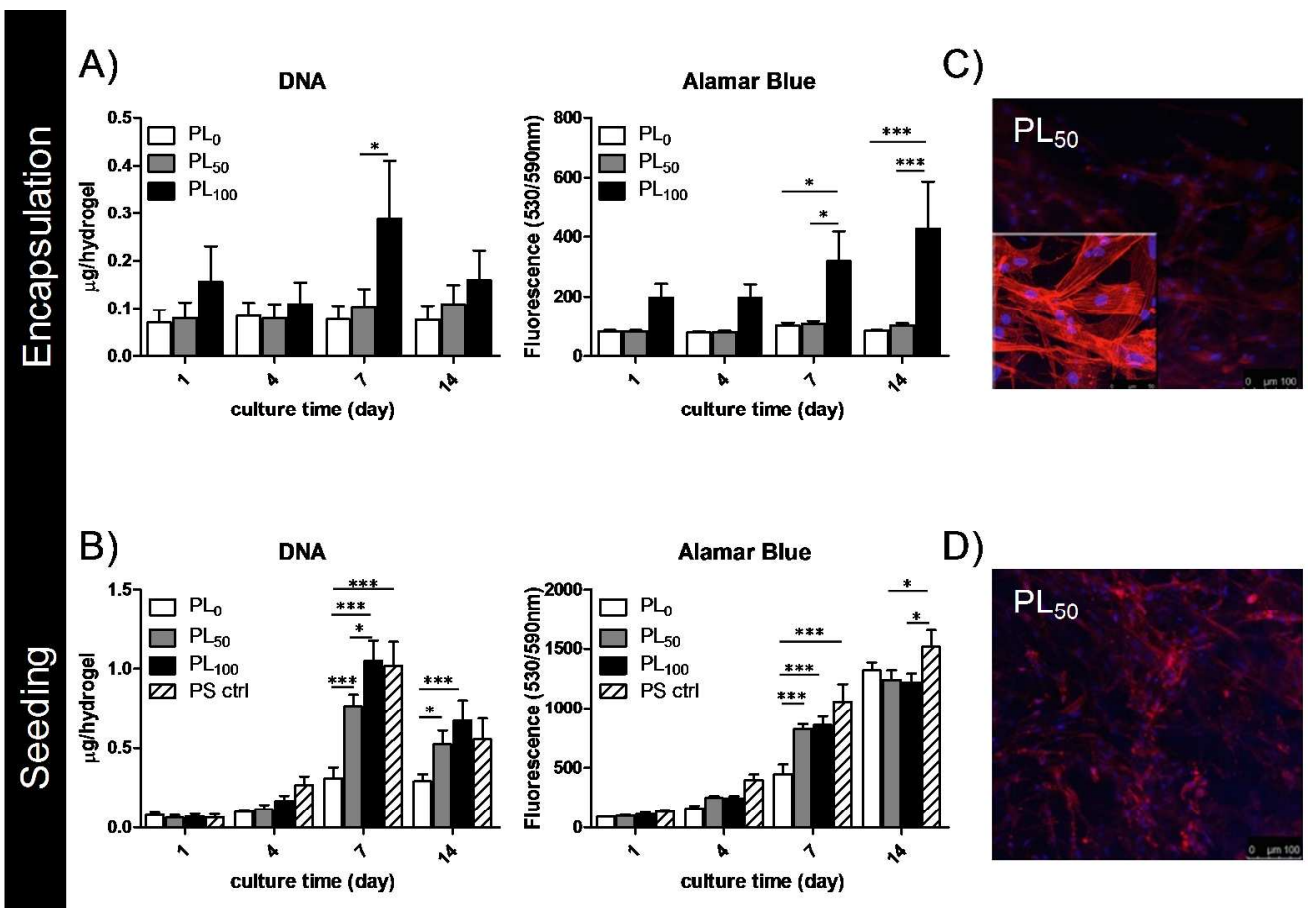

\section{$\mathrm{PL}_{100}$}

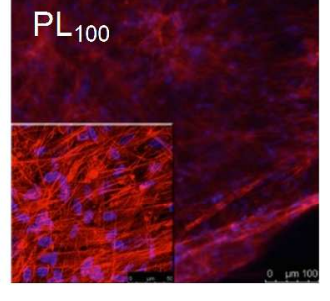

Figure 5. Response of hPDLFs seeded/encapsulated on the hydrogels with the formulations $\mathrm{PL}_{0}$, $\mathrm{PL}_{50}, \mathrm{PL}_{100}$. A) DNA quantification and metabolic activity of encapsulated cells. B) DNA quantification and metabolic activity of seeded cell. C) Representative pictures of hPDLFs encapsulated in $\mathrm{PL}_{50}$ and $\mathrm{PL}_{100}$ hydrogels, stained with DAPI (Blue) and Phalloidin (Red). for 21 days. The small micrographs on the bottom left depict the spindle-like shape morphology of the hPDLFs encapsulated into the hydrogels. D) hPDLFs seeded on $\mathrm{PL}_{50}$ and $\mathrm{PL}_{100}$ hydrogels and cultured for 21 days, stained with DAPI (Blue) and Phalloidin (Red). 
The results presented in Figure 5A show that there were no significant differences between the $\mathrm{PL}_{0}$ and $\mathrm{PL}_{50}$ hydrogels with respect to proliferation and metabolic activity of encapsulated cells. Remarkably, $\mathrm{PL}_{100}$ hydrogels exhibited higher cell growth and metabolic activity than $\mathrm{PL}_{0}$ and $\mathrm{PL}_{50}$ hydrogels. Regarding the morphology of the encapsulated cells, Figure $5 \mathrm{~B}$ shows that hPDLFs dispersed and stretched inside of the hydrogels, following the alignments of the fibrous structures observed macroscopically in the hydrogels.

The Figure 5C shows the behaviour of the hPDLFs cells when seeded at the surface of the $\mathrm{PL}_{0}$, $\mathrm{PL}_{50}$ and $\mathrm{PL}_{100}$ hydrogels. No significant differences were seen in terms of seeding efficiency on the hydrogels and on the PS positive control.

The analysis of hPDLFs distribution throughout the PL-enriched hydrogels, obtained by confocal microscopy from $\mathrm{PL}_{100}$ hydrogels 21 days after being seeded on the surface, is represented in Figure 6. This picture shows that hPDLFs seeded in the surface of the hydrogels migrated up to $70 \mu \mathrm{m}$ deep into to the hydrogel after 21 days in culture.

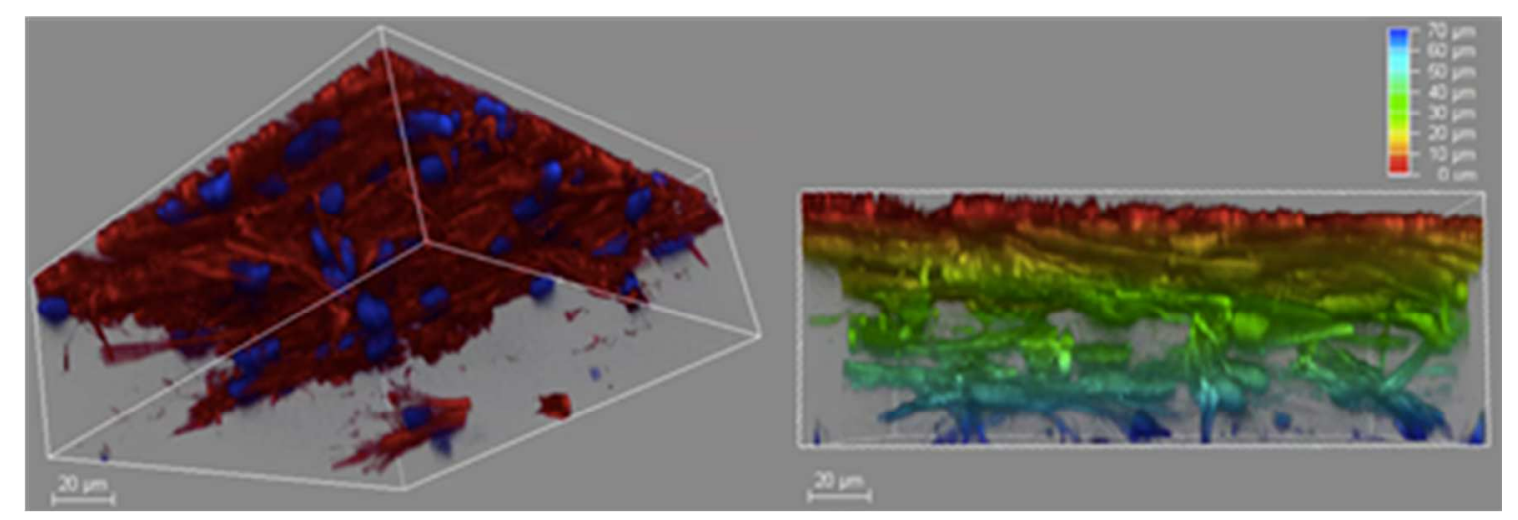

Figure 6. Three-dimensional reconstruction obtained by confocal microscopy of hPDLFs distribution on $\mathrm{PL}_{100}$ hydrogels at day 21 


\section{Antimicrobial activity}

The antimicrobial effect of PL soluble factors against Pseudomonas aeruginosa, Candida albicans, Escherichia Coli, Bacillus megaterium, Staphylococcus (VRSA), and Staphylococcus (MRSA), was evaluated.

The antimicrobial properties of the developed hydrogels containing PL were assessed using the agar well diffusion method, adapted from the Kirby-Bauer original method for testing microbial resistance to antibiotic drugs. The Figure 7 shows the effect of the hydrogels incorporating increasing amounts of PL in the Pseudomonas aeruginosa, Candida albicans, and Escherichia coli and e, Bacillus megaterium, vancomycin resistant Staphylococcus aureus (VRSA), methicillin resistant Staphylococcus aureus (MRSA).

The release of PL provides antimicrobial action against methicillin resistant Staphylococcus aureus, as shown by the inhibition of growth in the space occupied by the $\mathrm{PL}_{100}$ hydrogel (Figure 7F). Moreover, it is dependent on the PL content, since no inhibition hallo was observed for the formulations with lower amounts of PL incorporated $\left(\mathrm{PL}_{0}\right.$ and $\left.\mathrm{PL}_{50}\right)$. Nevertheless, despite no inhibition halo was observed in the rest of the species for the formulations investigated, no degradation or bacterial growth on the hydrogel surface was reported. 


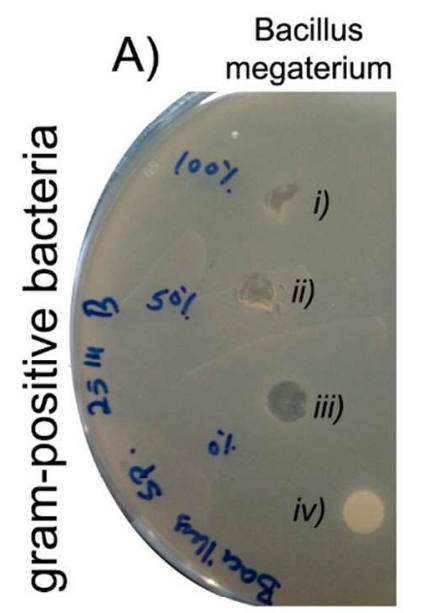

B) Staphylococcus. aureus

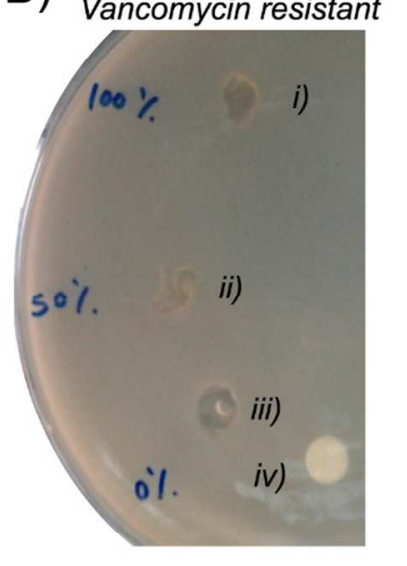

C) Staphylococcus aureus

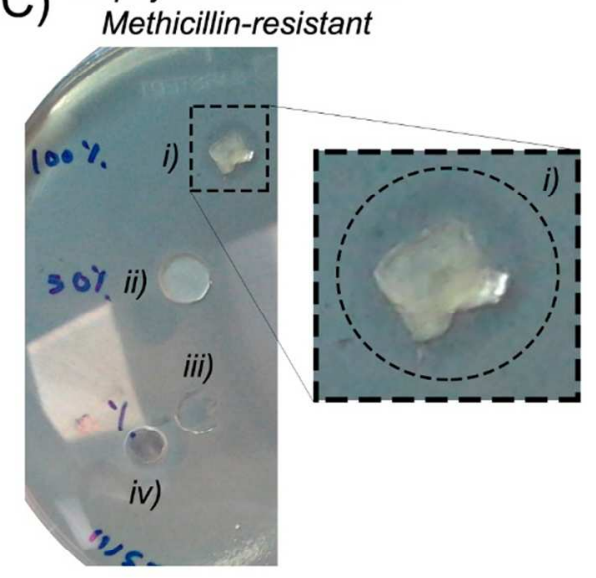

D) Pseudomonas

E) Escherichia Coli
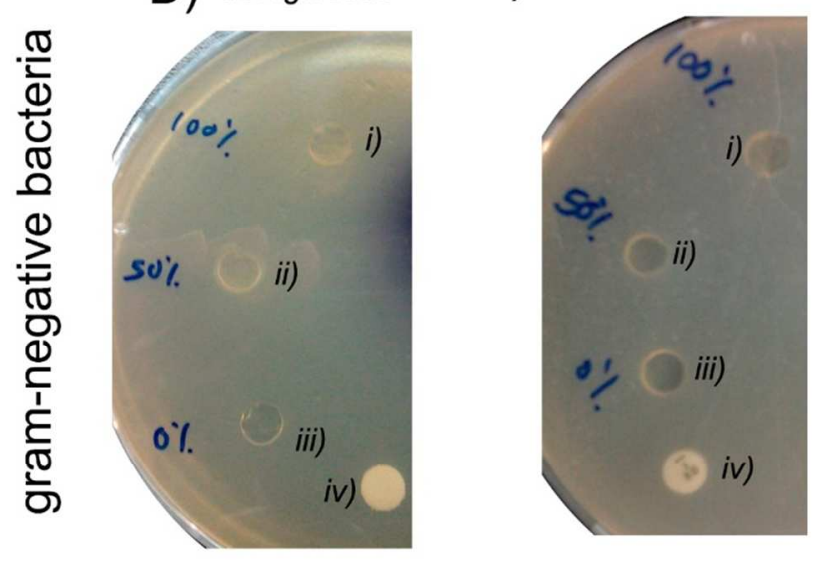

F) Candida

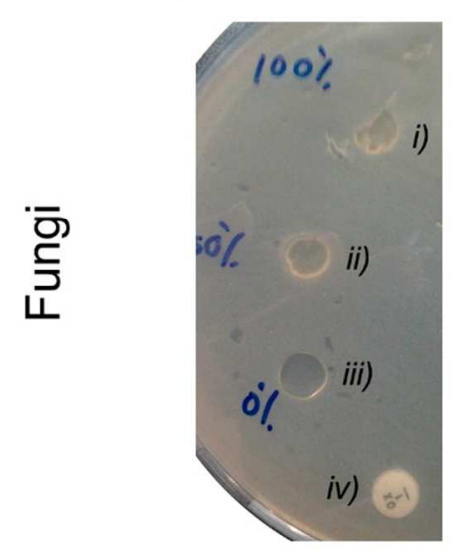

Figure 7. Antimicrobial assay for $\mathrm{PL}_{100}$ (i) $\mathrm{PL}_{50}$ (ii) and $\mathrm{PL}_{0}$ (iii) formulations where control is PBS (iv) using A) Pseudomonas aeruginosa, B) Candida albicans C) Escherichia Coli (E.Coli) D) Bacillus megaterium E) Vancomycin resistant Staphylococcus aureus (VRSA) F) Methicillin resistant Staphylococcus aureus (MRSA).

\section{DISCUSSION}

The present work describes the development of novel photocrosslinkable hydrogels incorporating allogenic platelet lysate, a platelet rich hemoderivative (PRHd), aimed at endogenous regenerative technology (ERT) being used for the regeneration of periodontal 
ligament. PL can be used in clinical applications as an autologous therapy. However, several authors ${ }^{5,24}$ have reported high donor-to-donor variability in PRHds batches, which could correlate with the high variability associated with the clinical outcomes of PRHds treatments ${ }^{25}$. On the other hand, Crespo-Diaz et al. ${ }^{5}$ reported lower variability in PL batches produced from outdated platelet concentrates obtained by plasma apheresis from different donors; therefore more predictable therapeutic outcomes could be anticipated. Furthermore, these PL batches were shown to be safe of standard pathogens and infectious diseases. In the present work, were used outdated ( $>5$ days old) platelet concentrates obtained by plasma apheresis and biologically qualified according to Portuguese legislation (Decreto-Lei No. 100/2011) for blood products collection, transport and therapeutic administration. Therefore, these PL batches are expected to be as save as any other blood component aimed for therapeutic administration and used in allogenic PL-based strategy as proposed. The combination of me-HA with PL, as herein proposed, produced a photocrosslinkable system with several advantages for tissue engineering applications. Being injectable, these biomaterials can be implanted using minimally invasive techniques without requiring surgical interventions. Moreover, the system can fit perfectly to irregular shaped defects, deeply interacting with the preserved tissue margins, before being photocrosslinked to produce a stable matrix.

With regard to viscoelastic properties, DMA analysis revealed that these hydrogels exhibit elastic modulus ranging from $264 \pm 81 \mathrm{kPa}$ for the $\mathrm{PL}_{0}$ formulation to $600 \pm 186 \mathrm{kPa}$ to the $\mathrm{PL}_{100}$ formulation (at $1 \mathrm{~Hz}$ ), comparable to other HA hydrogels incorporating fibrin described for artificial cartilage implantation $(445 \mathrm{kPa})^{26}$, which support the use of our photocrosslinkable hydrogels for soft tissue reconstruction. Moreover, periodontal tissue is continuously subjected to very dynamic forces, acting the periodontal ligament as a damper ${ }^{27-28}$. Therefore, the 
viscoelastic properties displayed by the hydrogels herein developed are of paramount importance for periodontal therapy approaches.

Regarding the degradation of HA hydrogels, it was faster in the presence of the HAase, the specific enzymes that degrade the HA in $v i v o^{29}$, than in saline solution, as previously reported ${ }^{13}$, 30. Remarkably, the PL enriched hydrogels remained stable for longer periods. The time to total degradation of $\mathrm{PL}_{100}$ was even longer when compared with other HA hydrogels exposed to similar conditions ${ }^{13}$. It should be noted that in this study was used a supra-physiologic concentration of HAase $(100 \mathrm{U} / \mathrm{mL})$, that in human plasma range from $0.0028 \pm 0.0004 \mathrm{U} / \mathrm{L}$ to $3.8 \pm 0.7 \mathrm{U} / \mathrm{L}$ depending on patient health condition ${ }^{31}$. Therefore, these findings suggest that PLenriched photocrosslinkable HA hydrogels, may maintain the necessary space stability in vivo for new tissue ingrowth ${ }^{4}$. Such reinforcement is attributed to the presence of fibrinogen in the $\mathrm{PL}^{1,18}$, as this protein is capable of crosslinking, forming a fibrin mesh which is not susceptible to degradation by the HAase. The fibrin/fibrinogen interact specifically with HA for the formation of ECM either during wound healing or in normal tissues ${ }^{32}$. This result is in line with previous studies in which HA hydrogels incorporating fibrin were proposed for cartilage repair ${ }^{26}$ given their improved biomechanical properties and the ability to provide an adequate environment for cell encapsulation.

The total PL-proteins release kinetics from the HA hydrogels herein developed was characterized by an initial "burst", followed by a sustained release over time. The release profile observed can be explained by two different processes: 1) the fast elution of large amount of the soluble proteins that are not physically interacting with the HA mesh, facilitated by the strong initial swelling of roughly two times the hydrogel initial weight; 2) a slow release of the proteins entrapped in the hydrogel mesh or adherent to the mesh, that are released by the physical 
degradation of the hydrogel. Since the PL proteins have different isoeletric points (pI), the electrostatic interactions and probability of remaining adsorbed to the HA mesh, which are negatively charged at physiologic $\mathrm{pH}$, will vary. In this way, the albumin, which is the main soluble protein in $\mathrm{PL}^{33}$, with an acidic $\mathrm{pI}$ (at $\mathrm{pH} 4.7$ ), is expected to be easily washed out from the HA mesh. On the other hand, most of the GFs present in PL with therapeutic interest have basic $\mathrm{pI}$ (TGF- $\beta$ at $\mathrm{pH}$ 8.90; PDGF-A at $\mathrm{pH}$ 9.52; PDGF-B at $\mathrm{pH} 9.39$; VEGF-1 at $\mathrm{pH}$ 8.66; FGF-2 at $\mathrm{pH}$ 9.6). So, they are expected to bind electrostatically to the HA matrix and to the insoluble PL proteins to be further released by ion exchange or by the degradation of the HA mesh promoted by HAses released for the ECM remodeling promoted during the wound healing process. In fact, the release of PL-specific GFs from the photocrosslinkable hydrogels, namely FGF-2, was only detected after degradation of the hydrogels in HAase (Figure 4B), while no detectable traces of GFs were detected after incubation of the hydrogels in PBS. Studies with FGF-2 have shown that this GF upregulate the migration and proliferation of PDL cells ${ }^{34}$. In fact, in order to fully regenerate functional of periodontal tissues, several GFs and cytokines should interplay in a temporal as spatial controlled manner ${ }^{10}$. Therefore, the controlled release of growth factors is a real asset to our hydrogels.

In line with what has been reported in literature, our findings show that the encapsulation of hPDLFs in non-supplemented HA hydrogels $\left(\mathrm{PL}_{0}\right)$ affects cell proliferation and metabolic activity. The biological performance of cells encapsulated in me-HA hydrogels is affected by the concentration of the macromer ${ }^{13,35}$, as well as by the concentration of photoinitiator ${ }^{35}$. Furthermore, the exposure to UV radiation was also reported to have adverse effects on viability and cell cycle progression, while the differentiation potential remains unchanged ${ }^{35}$. Remarkably, the adverse effects of photo-encapsulation were overcome by the incorporation of PL into the 
hydrogels. The viability and metabolic activity of the encapsulated hPDLFs increased proportionally with the incorporation of PL. Previous works have reported the positive effect of PL in the proliferation and maintenance of stemness phenotype of human periodontal ligament stem cells ${ }^{36}$. In the same line, we observed, in previous works that (hPDLFs) adhere and proliferate in genipin-crosslinked PL membranes ${ }^{37}$. It is known that platelets release several growth factors, namely PDGF and FGF-2, which have a mitogenic effect over human periodontal ligament cells $^{38-39}$. Moreover, PDGF and FGF-2 have been reported to have chemotactic properties over hPDLFs ${ }^{34,40}$, while the adhesion sites provided by the clot-forming proteins present in PL should facilitated the inward cell migration observed (Figure 6). Therefore, a strategy that can recruit progenitor cells from the preserved periodontal tissue and promote their proliferation and maintenance of stemness to colonize the periodontal defect with cells with great potential to regenerate periodontal tissue would be a valuable asset for periodontal ERT. Hereupon, the first intentional repair promoted by cells originated from periodontal tissues could partially restore the primitive anatomy and function of the periodontium ${ }^{4}$.

Finally, we have studied the antimicrobial properties of the developed hydrogels, a very important aspect considering the target application. It is known that the main cause of periodontal disease, as well as the main factor of rejection for some of the GTR techniques, is bacterial infections ${ }^{41-42}$. The HA was previously described to have bacteriostatic properties against oral and non-oral bacteria ${ }^{43}$. Carlson et al. ${ }^{43}$ suggested that the bacteriostatic effect of HA may be due to the saturation of the bacterial hyaluronate lyase by the excess HA, which prevents the bacteria from maintaining elevated levels of tissue permeability and penetrating the physical defenses of the host. This would enhance the ability of the host's immune system to eradicate 
pathogens. HA molecules in the hydrogels also form a random network of chains that may act as a sieve preventing the spread of the bacteria. Platelet concentrate (PC) was previously reported to have antimicrobial properties ${ }^{12}$ significantly reducing the growth of methicillin -sensitive or resistant Staphylococcus aureus, Group A Streptococcus, and Neisseria gonorrhea, among others. Being PL a product of PC activation by freeze/thaw cycles, the same would be expected for this hemoderivative. The obtained results in this study meet with the antimicrobial properties already described in the literature for platelet concentrates ${ }^{12}$. Here, the methicillin resistant Staphylococcus aureus (MRSA) was more susceptible to the hydrogels containing $\mathrm{PL}_{100}$ than the other microbial strains tested. Yeaman and Bayer proposed that the bactericidal activity against MRSA involved $\beta$-lysin, which is responsible for blood clotting found after platelets activation ${ }^{44-}$ 45. $\beta$-lysin, which is one of the most abundant compound found in PL after activation ${ }^{46}$ has been described to act against bacteria cell-wall, rapidly killing and stopping bacteria reproduction ${ }^{44-45}$, which could explain the results from this study. In addition, other PL-derived molecules with antibacterial properties against Gram + bacteria could be involved in this response, such as neutrophil activating protein-2 demonstrated capacity to kill Gram-positive and Gram-negative bacteria $^{47-48}$. Although no effect was observed against Gram- bacteria and fungus, other factors can be found in PL with bactericidal and fungicidal activity. For instance, Platelet factor-4 can bind to Gram-negative bacteria since it has an affinity for the lipopolysaccharide from these bacteria, facilitating their clearance ${ }^{49-50}$. Nevertheless, further investigation is needed in order to fully understand PL antimicrobial properties against microbial pathogens, especially whether the molecules that demonstrate antimicrobial potential interact alone or together when supplemented as PL and not from induced platelets. 


\section{CONCLUSIONS}

Overall, our findings demonstrate that is possible to obtain versatile photocrosslinkable HA-PL hydrogels that provide adequate substrates for hPDLFs attachment and growth while enabling the sustained release of PL and inhibit bacterial growth. Besides providing adequate space and stability, as well as biochemical cues for the regeneration of the lost tissues the hydrogels developed in this study present antimicrobial properties, which can contribute for the prophylaxis, preventing recurrent microbiotic colonization of the periodontal wound. These results suggest the great potential of these materials as cell and/or autologous growth factors carriers for endogenous regenerative technology (ERT) envisioning tissue engineering approaches targeting various tissues, namely the periodontal ligament.

\section{AUTHOR INFORMATION}

\section{Corresponding Author}

*Manuela E. Gomes; e-mail: megomes@dep.uminho.pt

\section{Author Contributions}

The manuscript was written through contributions of all authors. All authors have given approval to the final version of the manuscript.

\section{Funding Sources}

The research leading to these results has received funding from Fundação para a Ciência e a Tecnologia (FCT) under project BIBS (PTDC/CVT/102972/2008) and project ACROSS (PTDC/BBB-BIO/0827/2012), from the European Union Seventh Framework Programme (FP7/2007-2013) under grant agreement number REGPOT-CT2012-316331-POLARIS and from 
the project "Novel smart and biomimetic materials for innovative regenerative medicine approaches" RL1 - ABMR - NORTE-01-0124-FEDER-000016 cofinanced by North Portugal Regional Operational Programme (ON.2 - O Novo Norte), under the National Strategic Reference Framework (NSRF), through the European Regional Development Fund (ERDF).

\title{
ACKNOWLEDGMENT
}

The authors would like to thank Mariana Oliveira for the support in the dynamic mechanical analysis experiments; Dr. Celia Manaia from the Escola Superior de Biotecnologia (Porto, Portugal) for providing the Pseudomonas sp. bacteria; and Dr. Alberta Faustino from the Hospital de S. Marcos (Braga, Portugal) for providing the other bacterial strains. Pedro S. Babo, and Albina Franco acknowledge FCT for the PhD grant SFRH/BD/73403/2010 and Post-Doc grant SFRH/BPD/100760/2014.

\author{
ABBREVIATIONS \\ PL, Platelet Lysate; hPDLFs, human Periodontal Ligament fibroblasts; GTR, guided tissue \\ regeneration; HAase, hyaluronidase; ERT, endogenous regenerative technology; MRSA, \\ Methicillin Resistant Staphylococcus aureus; VRSA, Vancomycin Resistant Staphylococcus \\ aureus; HA, hyaluronic acid; me-HA, methacrylated hyaluronic acid; GFs, growth factors; $\alpha-$ \\ MEM, minimum essential medium eagle alpha modification; PDMS, polydimethylsiloxane; MA, \\ methacrylic anhydride; $\mathrm{dH}_{2} \mathrm{O}$, distilled water; FTIR, fourier transform infrared spectroscopy; \\ ${ }^{1} \mathrm{HNMR}$, Proton nuclear magnetic resonance; Dmet, degree of methacrylation; $\mathrm{PL}_{0}$, hydrogel \\ incorporating $0 \mathrm{v} / \mathrm{v} \%$ of PL; PL 50 , hydrogel incorporating $50 \mathrm{v} / \mathrm{v} \%$ of PL; $\mathrm{PL}_{100}$, hydrogel \\ incorporating $100 \mathrm{v} / \mathrm{v} \%$ of PL; HAPL, hyaluronic acid hydrogels incorporating PL; mwet, \\ hydrogel wet mass; $m d r y$, dry hydrogel mass; $m_{i}$, initial weight; $m_{f}$, final weight; ELISA,
}


Enzyme-Linked Immunosorbent Assay; FGF-2, fibroblast growth factor-2; MH, Muller-Hinton

(agar); DMA, dynamic mechanical analysis, pI, isoelectric point.

\section{REFERENCES}

1. Chen, F. M.; Jin, Y., Periodontal tissue engineering and regeneration: current approaches and expanding opportunities. Tissue engineering. Part B, Reviews 2010, 16 (2), 219-55. DOI: 10.1089/ten.TEB.2009.0562.

2. Susin, C.; Wikesjö, U. M. E., Regenerative periodontal therapy: 30 years of lessons learned and unlearned. Periodontology 2000 2013, 62 (1), 232-242. DOI: 10.1111/prd.12003.

3. Chen, F. M.; Zhang, J.; Zhang, M.; An, Y.; Chen, F.; Wu, Z. F., A review on endogenous regenerative technology in periodontal regenerative medicine. Biomaterials 2010, 31 (31), 7892927. DOI: 10.1016/j.biomaterials.2010.07.019.

4. Polimeni, G. X., A. V.; Wikesjo U. M., Biology and principles of periodontal wound healing/regeneration. Periodontology 2000 2006, 41 (41), 30-47.

5. Crespo-Diaz, R.; Behfar, A.; Butler, G. W.; Padley, D. J.; Sarr, M. G.; Bartunek, J.; Dietz, A. B.; Terzic, A., Platelet lysate consisting of a natural repair proteome supports human mesenchymal stem cell proliferation and chromosomal stability. Cell transplantation 2011, 20 (6), 797-811. DOI: 10.3727/096368910X543376.

6. $\quad$ Fekete, N.; Gadelorge, M.; Furst, D.; Maurer, C.; Dausend, J.; Fleury-Cappellesso, S.; Mailander, V.; Lotfi, R.; Ignatius, A.; Sensebe, L.; Bourin, P.; Schrezenmeier, H.; Rojewski, M. T., Platelet lysate from whole blood-derived pooled platelet concentrates and apheresis-derived platelet concentrates for the isolation and expansion of human bone marrow mesenchymal stromal cells: production process, content and identification of active components. Cytotherapy 2012, 14 (5), 540-54. DOI: 10.3109/14653249.2012.655420.

7. Kurita, J.; Miyamoto, M.; Ishii, Y.; Aoyama, J.; Takagi, G.; Naito, Z.; Tabata, Y.; Ochi, M.; Shimizu, K., Enhanced vascularization by controlled release of platelet-rich plasma impregnated in biodegradable gelatin hydrogel. The Annals of thoracic surgery 2011, 92 (3), 837-44; discussion 844. DOI: 10.1016/j.athoracsur.2011.04.084.

8. Matsui, M.; Tabata, Y., Enhanced angiogenesis by multiple release of platelet-rich plasma contents and basic fibroblast growth factor from gelatin hydrogels. Acta biomaterialia 2012, 8 (5), 1792-801. DOI: 10.1016/j.actbio.2012.01.016.

9. Sipe, J. B.; Zhang, J.; Waits, C.; Skikne, B.; Garimella, R.; Anderson, H. C., Localization of bone morphogenetic proteins (BMPs)-2, -4 , and -6 within megakaryocytes and platelets. Bone 2004, 35 (6), 1316-22. DOI: 10.1016/j.bone.2004.08.020.

10. Chen, F. M.; An, Y.; Zhang, R.; Zhang, M., New insights into and novel applications of release technology for periodontal reconstructive therapies. Journal of controlled release : official journal of the Controlled Release Society 2011, 149 (2), 92-110. DOI: 10.1016/j.jconrel.2010.10.021.

11. Marx, R. E., Platelet-rich plasma: evidence to support its use. Journal of oral and maxillofacial surgery : official journal of the American Association of Oral and Maxillofacial Surgeons 2004, 62 (4), 489-96.

12. Adam Hacking, S.; Khademhosseini, A., Cells and Surfaces in vitro. In Biomaterials Science (Third Edition), Hoffman, A. S.; Schoen, F. J.; Lemons, J. E., Eds. Academic Press: 2013; pp 408-427. DOI: http://dx.doi.org/10.1016/B978-0-08-087780-8.00037-1. 
13. Burdick, J. A.; Chung, C.; Jia, X.; Randolph, M. A.; Langer, R., Controlled degradation and mechanical behavior of photopolymerized hyaluronic acid networks. Biomacromolecules 2005, 6 (1), 386-91. DOI: 10.1021/bm049508a.

14. Collins, M. N.; Birkinshaw, C., Hyaluronic acid based scaffolds for tissue engineering--a review. Carbohydrate polymers 2013, 92 (2), 1262-79. DOI: 10.1016/j.carbpol.2012.10.028.

15. Dahiya, P.; Kamal, R., Hyaluronic Acid: a boon in periodontal therapy. North American journal of medical sciences 2013, 5 (5), 309-15. DOI: 10.4103/1947-2714.112473.

16. Jentsch, H.; Pomowski, R.; Kundt, G.; Göcke, R., Treatment of gingivitis with hyaluronan. Journal of Clinical Periodontology 2003, 30 (2), 159-164. DOI: 10.1034/j.1600051X.2003.300203.x.

17. Sukumar, S.; Drizhal, I., Hyaluronic acid and periodontitis. Acta medica (Hradec Kralove) / Universitas Carolina, Facultas Medica Hradec Kralove 2007, 50 (4), 225-8.

18. Babo, P., Santo, V. E., Duarte, A. C., Correia, C., Costa, M., Mano, J. F., Reis, R. L. and Gomes, M. E., Platelet lysate membranes as new autologous templates for tissue engineering applications. Inflammation and Regeneration 2014, 34, 33-44.

19. Santo, V. E.; Gomes, M. E.; Mano, J. F.; Reis, R. L., Chitosan-chondroitin sulphate nanoparticles for controlled delivery of platelet lysates in bone regenerative medicine. Journal of tissue engineering and regenerative medicine 2012, 6 Suppl 3, s47-59. DOI: 10.1002/term.1519.

20. Smeds, K. A.; Pfister-Serres, A.; Miki, D.; Dastgheib, K.; Inoue, M.; Hatchell, D. L.; Grinstaff, M. W., Photocrosslinkable polysaccharides for in situ hydrogel formation. Journal of biomedical materials research 2001, 54 (1), 115-21.

21. Williams, C. G.; Malik, A. N.; Kim, T. K.; Manson, P. N.; Elisseeff, J. H., Variable cytocompatibility of six cell lines with photoinitiators used for polymerizing hydrogels and cell encapsulation. Biomaterials 2005, 26 (11), 1211-8. DOI: 10.1016/j.biomaterials.2004.04.024.

22. Ohno, S.; Ijuin, C.; Doi, T.; Yoneno, K.; Tanne, K., Expression and activity of hyaluronidase in human periodontal ligament fibroblasts. Journal of periodontology 2002, 73 (11), 1331-7. DOI: 10.1902/jop.2002.73.11.1331.

23. Bauer, A. W.; Kirby, W. M.; Sherris, J. C.; Turck, M., Antibiotic susceptibility testing by a standardized single disk method. American journal of clinical pathology 1966, 45 (4), 493-6.

24. Weibrich, G.; Kleis, W. K.; Hafner, G.; Hitzler, W. E., Growth factor levels in plateletrich plasma and correlations with donor age, sex, and platelet count. Journal of cranio-maxillofacial surgery : official publication of the European Association for Cranio-Maxillo-Facial Surgery 2002, 30 (2), 97-102. DOI: 10.1054/jcms.2002.0285.

25. Wang, H.-L.; Avila, G., Platelet Rich Plasma: Myth or Reality? European journal of dentistry 2007, 1 (4), 192-194.

26. Rampichova, M.; Filova, E.; Varga, F.; Lytvynets, A.; Prosecka, E.; Kolacna, L.; Motlik, J.; Necas, A.; Vajner, L.; Uhlik, J.; Amler, E., Fibrin/hyaluronic acid composite hydrogels as appropriate scaffolds for in vivo artificial cartilage implantation. ASAIO journal 2010, 56 (6), 563-8. DOI: 10.1097/MAT.0b013e3181 fcbe24.

27. Dorow, C.; Krstin, N.; Sander, F. G., Determination of the mechanical properties of the periodontal ligament in a uniaxial tensional experiment. Journal of orofacial orthopedics = Fortschritte der Kieferorthopadie : Organ/official journal Deutsche Gesellschaft fur Kieferorthopadie 2003, 64 (2), 100-7. DOI: 10.1007/s00056-003-0225-7.

28. Beertsen, W.; McCulloch, C. A.; Sodek, J., The periodontal ligament: a unique, multifunctional connective tissue. Periodontology 2000 1997, 13, 20-40. 
29. Houck, J. C.; Pearce, R. H., The mechanism of hyaluronidase action. Biochim Biophys Acta 1957, 25, 555-562. DOI: http://dx.doi.org/10.1016/0006-3002(57)90527-9.

30. Yong Doo Park, N. T., Jeffrey A. Hubbell, Photopolymerized hyaluronic acid-based hydrogels and interpenetrating networks. Biomaterials 2003, 24, 893-900.

31. Kucur, M.; Karadag, B.; Isman, F. K.; Ataev, Y.; Duman, D.; Karadag, N.; Ongen, Z.; Vural, V. A., Plasma hyaluronidase activity as an indicator of atherosclerosis in patients with coronary artery disease. Bratislavske lekarske listy 2009, 110 (1), 21-6.

32. LeBoeuf, R. D.; Raja, R. H.; Fuller, G. M.; Weigel, P. H., Human fibrinogen specifically binds hyaluronic acid. The Journal of biological chemistry 1986, 261 (27), 12586-92.

33. Burkhart, J. M.; Vaudel, M.; Gambaryan, S.; Radau, S.; Walter, U.; Martens, L.; Geiger, J.; Sickmann, A.; Zahedi, R. P., The first comprehensive and quantitative analysis of human platelet protein composition allows the comparative analysis of structural and functional pathways. Blood 2012, 120 (15), e73-82. DOI: 10.1182/blood-2012-04-416594.

34. Shimabukuro, Y.; Terashima, H.; Takedachi, M.; Maeda, K.; Nakamura, T.; Sawada, K.; Kobashi, M.; Awata, T.; Oohara, H.; Kawahara, T.; Iwayama, T.; Hashikawa, T.; Yanagita, M.; Yamada, S.; Murakami, S., Fibroblast growth factor-2 stimulates directed migration of periodontal ligament cells via PI3K/AKT signaling and CD44/hyaluronan interaction. Journal of cellular physiology 2011, 226 (3), 809-21. DOI: 10.1002/jcp.22406.

35. Fedorovich, N. E.; Oudshoorn, M. H.; van Geemen, D.; Hennink, W. E.; Alblas, J.; Dhert, W. J., The effect of photopolymerization on stem cells embedded in hydrogels. Biomaterials 2009, 30 (3), 344-53. DOI: 10.1016/j.biomaterials.2008.09.037.

36. Wu, R. X.; Yu, Y.; Yin, Y.; Zhang, X. Y.; Gao, L. N.; Chen, F. M., Platelet lysate supports the in vitro expansion of human periodontal ligament stem cells for cytotherapeutic use. Journal of tissue engineering and regenerative medicine 2016. DOI: 10.1002/term.2124.

37. Babo, P. S.; Klymov, A.; teRiet, J.; Reis, R. L.; Jansen, J. A.; Gomes, M. E.; Walboomers, X. F., A Radially Organized Multipatterned Device as a Diagnostic Tool for the Screening of Topographies in Tissue Engineering Biomaterials. Tissue engineering. Part $C$, Methods 2016, 22 (9), 914-22. DOI: 10.1089/ten.TEC.2016.0224.

38. Mumford, J. H.; Carnes, D. L.; Cochran, D. L.; Oates, T. W., The effects of plateletderived growth factor-BB on periodontal cells in an in vitro wound model. Journal of periodontology 2001, 72 (3), 331-40. DOI: 10.1902/jop.2001.72.3.331.

39. An, S.; Huang, X.; Gao, Y.; Ling, J.; Huang, Y.; Xiao, Y., FGF-2 induces the proliferation of human periodontal ligament cells and modulates their osteoblastic phenotype by affecting Runx2 expression in the presence and absence of osteogenic inducers. International journal of molecular medicine 2015, 36 (3), 705-11. DOI: 10.3892/ijmm.2015.2271.

40. Boyan, L. A.; Bhargava, G.; Nishimura, F.; Orman, R.; Price, R.; Terranova, V. P., Mitogenic and chemotactic responses of human periodontal ligament cells to the different isoforms of platelet-derived growth factor. Journal of dental research 1994, 73 (10), 1593-600.

41. Mandell, R. L.; Socransky, S. S., A selective medium for Actinobacillus actinomycetemcomitans and the incidence of the organism in juvenile periodontitis. Journal of periodontology 1981, 52 (10), 593-8. DOI: 10.1902/jop.1981.52.10.593.

42. Newman, M. G.; Socransky, S. S.; Savitt, E. D.; Propas, D. A.; Crawford, A., Studies of the microbiology of periodontosis. Journal of periodontology 1976, 47 (7), 373-9. DOI: 10.1902/jop.1976.47.7.373.

43. Carlson, G. A.; Dragoo, J. L.; Samimi, B.; Bruckner, D. A.; Bernard, G. W.; Hedrick, M.; Benhaim, P., Bacteriostatic properties of biomatrices against common orthopaedic pathogens. 
Biochemical and Biophysical Research Communications 2004, 321 (2), 472-478. DOI: http://dx.doi.org/10.1016/j.bbrc.2004.06.165.

44. Pastagia, M.; Schuch, R.; Fischetti, V. A.; Huang, D. B., Lysins: the arrival of pathogendirected anti-infectives. Journal of medical microbiology 2013, 62 (Pt 10), 1506-16. DOI: 10.1099/jmm.0.061028-0.

45. Schuch, R.; Lee, H. M.; Schneider, B. C.; Sauve, K. L.; Law, C.; Khan, B. K.; Rotolo, J. A.; Horiuchi, Y.; Couto, D. E.; Raz, A.; Fischetti, V. A.; Huang, D. B.; Nowinski, R. C.; Wittekind, M., Combination therapy with lysin CF-301 and antibiotic is superior to antibiotic alone for treating methicillin-resistant Staphylococcus aureus-induced murine bacteremia. The Journal of infectious diseases 2014, 209 (9), 1469-78. DOI: 10.1093/infdis/jit637.

46. Yeaman, R. M. B., S. A., Antimicrobial peptides from platelets. Drug Resistance Updates 1999, 2, 116-126.

47. Krijgsveld, J.; Zaat, S. A.; Meeldijk, J.; van Veelen, P. A.; Fang, G.; Poolman, B.; Brandt, E.; Ehlert, J. E.; Kuijpers, A. J.; Engbers, G. H.; Feijen, J.; Dankert, J., Thrombocidins, microbicidal proteins from human blood platelets, are C-terminal deletion products of CXC chemokines. The Journal of biological chemistry 2000, 275 (27), 20374-81.

48. Lam, F. W.; Vijayan, K. V.; Rumbaut, R. E., Platelets and their interactions with other immune cells. Comprehensive Physiology 2015, 5 (3), 1265-1280. DOI: 10.1002/cphy.c140074.

49. Krauel, K.; Weber, C.; Brandt, S.; Zahringer, U.; Mamat, U.; Greinacher, A.; Hammerschmidt, S., Platelet factor 4 binding to lipid A of Gram-negative bacteria exposes PF4/heparin-like epitopes. Blood 2012, 120 (16), 3345-52. DOI: 10.1182/blood-2012-06434985.

50. Hamzeh-Cognasse, H.; Damien, P.; Chabert, A.; Pozzetto, B.; Cognasse, F.; Garraud, O., Platelets and infections - complex interactions with bacteria. Frontiers in immunology 2015, 6 , 82. DOI: 10.3389/fimmu.2015.00082.

Table of Contents Graphic 


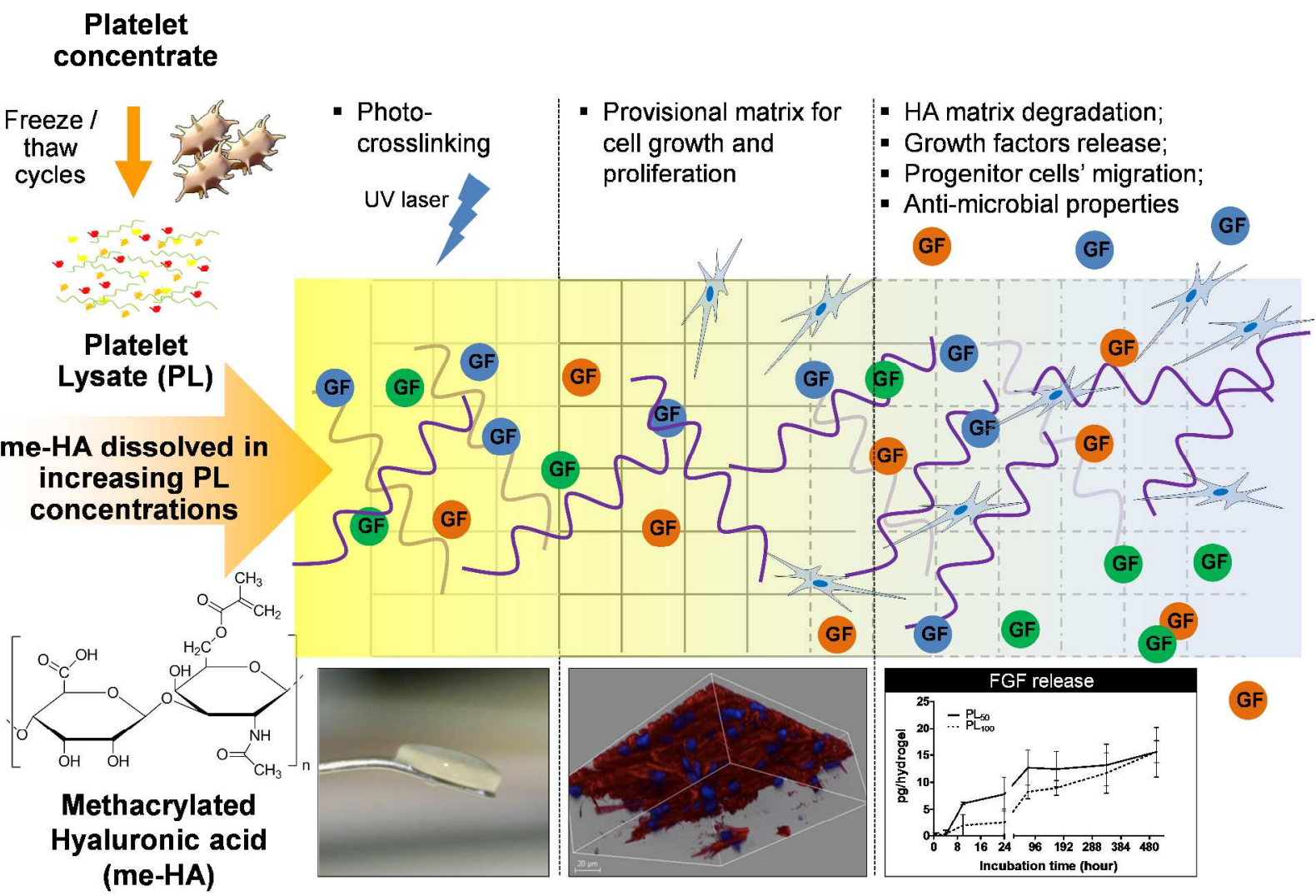

